\title{
The compelling arguments for the need of microvascular investigation in COVID-19 critical patients
}

\author{
Romeo Martini* \\ Unità Operativa di Angiologia, Azienda Ospedaliera Universitaria di Padova, Padova, Italy
}

\begin{abstract}
The burden of pandemic COVID-19 is growing worldwide, as the continuous increases of contagion. Only 10-15\% of the entire infected population has the necessity of intensive care unit (ICU) treatments. But, this relatively low rate of patients has absorbed almost the whole availability of ICU during few days, becoming at least in Italy, an emergency for the national health system. In COVID-19 ICU patients massive aggression of lung with severe pulmonary failure, as well as kidney and liver injuries, heart, brain, bowel and spleen damages with lymph nodes necrosis and even cutaneous manifestations have been observed. Moreover, increased levels of cytokines so-called "cytokines storm (CS), and overt intravascular disseminated coagulation have been also reported. The hypercoagulation and CS would speculate about a microvascular dysfunction. Unfortunately, no specific observations have been performed on microcirculatory dysfunction in COVID-19 patients. Hence the presumed pathophysiological pathways and models about a microvascular involvement can be gathered by sepsis models studies. But despite this lack of evidence, the COVID-19 has emphasized the compelling need for microcirculation monitoring at the bedside in ICU patients.
\end{abstract}

Keywords: Microcirculation, COVID-19, endothelial dysfunction

\section{Introduction}

In December 2019, the outbreak of Corona virus (SARS-CoV-2) in Wuhan, Hubei province, China, has induced a pandemic disease known as COVID-19 [1,2]. Up to date, this illness has caused a large number of fatalities all around the World [3]. In almost three months, in Italy, occurred more than 217,000 infections and almost 30,000 deaths [4].

The most of COVID-19 patients have complained only mild symptomatology, such as cough, fever, arthralgia and fatigue [5]. But, about 10\% has suffered from severe acute respiratory distress syndrome (ARDS) and multi-organ failure (MOF), needing intensive care unit (ICU) assistance [6]. This low proportion of patients, in a few weeks, has saturated most of the resources of ICU availability, becoming an emergency for the Italian national health system.

The majority of critical patients needing ICU treatments had a massive pulmonary failure, [5, 6] associated with alterations in the kidney, liver, heart, brain, bowel, and skin [7]. Moreover, some observations have reported very high levels of D-dimer, with a significant rate of venous thromboembolism, (deep venous thrombosis and pulmonary embolism), as well overt intravascular disseminated coagulation (IDC) [8]. Thrombocytopenia, lymphopenia and significant increased levels of cytokines have been found frequently in blood samples tests [9]. The elevated levels of cytokines, defined as cytokines storm (CS) [10], and the finding of ARDS and MOF have generated speculation about the development of severe microvascular hemodynamic ad hemorheology dysfunctions in ICU COVID-19 patients [11].

*Corresponding author: Romeo Martini. E-mail: romeo.martini@aopd.veneto.it. 
Whether the CS or the direct virus attack might provoke a microcirculatory dysfunction in COVID-19 patients it is not yet understood. To date, there are few studies of microvascular function in COVID-19 [12]. But, many previous studies have reported that CS can provoke massive microvascular dysfunction in critical ICU patients suffering from similar disease [13]. Furthermore, some of the treatments performed in ICU COVID-19 patients, base their rationale in the suppression of cytokines' actions [14].

Moreover, there is a lack of equipment that may allow a suitable assessment of microcirculation at the bedside [15]. Hand-held vital microscopy (HVM) is the only instrument that has shown accuracy at the bedside investigation of microcirculation in ICU critical patients [16-18]. But, its use is still poorly spread and limited. Hence the new Corona virus infection, has spotlighted the compelling need of beside microcirculation assessment in critical ICU patients. The direct observations of microvascular bed may improve the understanding of COVID-19.

This paper aims to be of help in supporting this need.

\section{The hypothesis of microvascular damage on COVID-19 patients: Cytokines storm and endothelial dysfunction}

Several authors have reported a very elevated number of cytokines and chemokines in patients affected by COVID-19. Cytokines such as tumor necrosis factor (TNF $\alpha$ ), interleukin 1B, IL-1RA, IL-2, IL-6, IL-7, IL-8, IL-9, IL-10 (IL-1ß), or chemokines as granulocyte-colony stimulating factor, interferon gamma-induced protein-10, monocyte chemoattractant protein-1, macrophage inflammatory proteins 1-, platelet-derived growth factor (PDGF) [19] have shown very high haematic levels in these patients. This event observed in the later phases of the disease and defined CS [20-22], has been described in previous coronavirus cases of pneumonia, such as severe acute respiratory syndrome (SARS) and the Middle East respiratory syndrome (MERS) [10, 24, 24]. But, in severe COVID-19 patients, its intensity has been much greater [10,25]. The CS is a reaction of the immune system to different causes such as tumors, sepsis, and virus infection too [10, 26].

Its consequence is the damage of many organs of the human body because induce endothelial cell dysfunction. The CS activates platelets, neutrophils, monocytes, and macrophages [10]. These haematic cells adhere to the adhesion molecules exposed by endothelial cells (EC) during inflammation. Consequently, the ECs mitochondria release reactive oxygen-derived free radicals (ROS) with a reduction of endothelial NO synthase (eNOS) activity and of nitric oxide (NO) levels [27, 28]. The $\mathrm{NO}$ is a key factor in endothelial microhaemodynamic regulatory activity. NO stimulate the guanylate cyclase, responsible for the synthesis of cyclic guanosine monophosphate (cGMP) that induces the relaxation of micro vessels myocells [29]. Moreover, erythrocytes deformability is altered and may aggregate with endothelial cells inducing further turbulence and dysfunction to micro hemodinamic perfusion [30]. But, as eNOS is not homogeneously expressed in different organs and different parts of each organ microvessel bed, the reduction of NO may result heterogeneously [16]. Consequently, hypo and hyperperfused areas may exist within each organ. This "shunted" perfusion may determine an ischemic organ condition that may persist longer than systemic hemodynamic recovering and determining the maintenance of organ failure.

The loss of endothelial barrier effect may be presumed in COVID-19 as interstitial edema is frequently reported in autopsies of patients $[31,32]$. Systemic hypoxia generated by ARDS is one of the main causes that may induce the release of vascular endothelial growth factor (VEGF) [33]. This molecule is related to Hypoxia-Inducible Factor 1, produced under hypoxic conditions [34, 35].

Therefore, it could be presumed that the severe pulmonary failure in COVID-19, may induce tissue hypoxia with a huge release of VEGF leading to massive interstitial lung edema. 


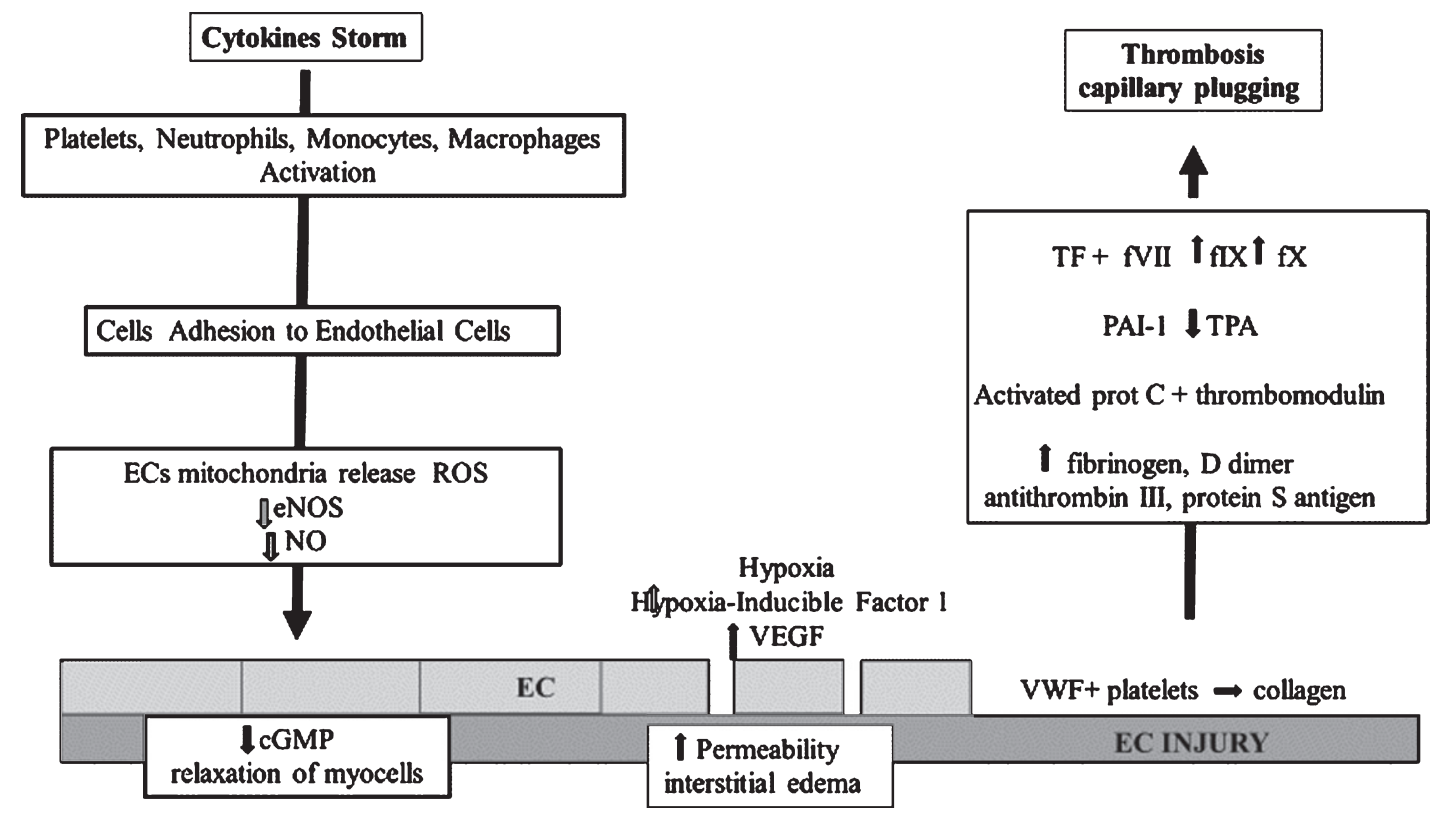

Fig. 1. Cytokines Storm and induced Endothelial dysfunction in COVID-19 : EC: Endothelial Cell; ROS: reactive oxygen species; eNOS: Endothelial Nitric Oxide Synthasis; NO: Nitric Oxide; cGMP: guanosine monophosphate; VEGF: Vascular endothelial growth factor; VWF: von Willebrand factor; PAI-1: plasminogen activator inhibitor type 1; TPA: tissue plasminogen activator; f VII: factor VII; fIX: factors IX; fX; factor X.

Finally, the EC regulates hemostasis via the production of the von Willebrand factor (VWF), tissue factor (TF), and plasminogen activator inhibitor type 1 (PAI-1) [36]. The VWF binds platelets to collagen components once ECs have been destroyed [9]; TF interacting with the factor VII, activates the factors IX and X; the PAI-1 regulates fibrinolysis by inhibiting tissue plasminogen activator [37-39]. The ECs activate also the protein $\mathrm{C}$ via thrombomodulin and endothelial protein $\mathrm{C}$ receptor, which inhibits factor V, factor VIII, and PAI-1 [40]. In severe COVID-19 patients, a procoagulant status is determined by an elevated level of fibrinogen, D dimer, Protein C, IgG anti-cardiolipin antibodies (ACA), anti-beta2-glycoprotein I (anti- $\beta 2-G P I)$, Factor VIII and VWF, both VWF antigen and activity. Moreover, a reduction of antithrombin III, protein $\mathrm{S}$ antigen have also been observed [8]. The resulting prothrombotic effects stimulate a further adhesion of leukocytes and platelets to the vascular endothelium, causing a further increase of endothelial dysfunction with vascular micro-thrombosis, capillary plugging, and greater impairment of capillary flow [41, 42].

In conclusion in COVID-19, the CS, in the late phase of the infection, may determine a microvascular dysfunction starting by EC injury, Fig. 1 .

The main events are a maldistribution of organ perfusion, the endothelial barrier leak, and a prothrombotic state. Associated with this pattern, other alterations of hemorheology such as compromised deformation of red blood cells, as well as leukocytes may induce capillary plugging and capillary thrombosis with microcirculatory stasis and increased tissue hypoxia. The clinical findings related to the microvascular dysfunction are ARDS and MOF with cardiac, renal, hepatic, brain, bowel and skin damages. The blood hypercoagulability with disseminated microvascular thrombosis may be also sustained by a diffuse and massive endothelial injury.

The CS then has a key role in the progression of the disease towards a critical stage and could be considered as a prognostic indicator of fatal events in COVID-19 [1, 19]. 


\section{The bedside microcirculation assessment in critical ICU patients}

The bedside microvascular evaluation remains a problematic issue. The major obstacle to its spread is the lack of available instruments with a good diagnostic accuracy [15].

To date, the only instrument that has shown good accuracy in the microvascular bedside assessment is the hand-held video microscopy used to observe the sublingual microcirculation [15].

Rather than other methodologies such as laser Doppler techniques or near-infrared spectroscopy, HVM allows the direct visualization of the microvascular bed permitting to assess the blood flow velocity and the capillary density. The HVM allows to monitor the patient' microcirculation functionality during his permanence in ICU and assesses his response to treatments $[15,16]$.

The clinical significance of sublingual microcirculation in representing the microcirculatory in other organ microcirculatory districts has been demonstrated in several studies [43-46]. Moreover, the HVM has proved how sublingual microcirculation is much more sensitive and specific than macro haemodynamic variables, in predicting patient morbidity and mortality [47-53]. The relevance of HVM has been highlighted in an international consensus paper on the measurement of sublingual microcirculation in critically ill patients by the European Society for Intensive Care Medicine [54].

However, as reported by Miranda, the ideal instrument for monitoring microcirculation at the patient bedside should not only be limited to the direct non-invasive visualization of the capillary, but should be able to integrate the hemodynamic parameters with biomarkers of vascular permeability, inflammatory response, coagulation, and transport of oxygen to the tissue [16].

The biomarkers are difficult to interpret and expensive to dose in blood samples. Indeed, the lactate, is widely used to assess tissue hypoperfusion but, the increased lactate production may not only be related to anaerobic metabolism. Other not hypoxic mechanisms anaerobic may increase the lactate level. On the contrary tissue hypoperfusion may be present if lactate is not elevated $[15,55]$.

Furthermore, circulating ECs may indicate direct endothelial damage [56] as well as proteases, VCAMs, and other selectins and integrins levels that are increased during inflammation [57]. However, most of the biomarkers above reported have uncertain origin because of the heterogeneity of the endothelium among organs and vessels of each organ [58].

Regarding tissue oxygen assessment we are still far from having reliable test or instruments that can be utilised to measure the oxygen quantity that tissue needs [16]. But, this argument is not the focus of this paper. The target of this document is to reports the urgent needs for improve efforts to spread the bedside assessment of microcirculation in critical ill patient.

But, it is well known that the restoring of body optimal perfusion sometimes is not coherent with the recovery of organs function. This may be due to the persistence of microvascular dysfunction in each single body organ, such as micro-thrombosis, capillary stasis with shunted perfusion, or interstitial edema. To date, in clinical practice, the recovery of organ perfusion is assessed by the monitoring of the macro-hemodynamic parameters associated with laboratory indexes of organ functionality or lactates. Conventional macro-hemodynamic parameters fail to intercept the microcirculatory dysfunction.

\section{Is the beside microcirculation assessment a compelling need in critical ICU COVID-19 patients?}

The direct assessment of the microcirculatory bed using HVM integrated with available biomarkers could provide useful information to compare with patient clinical status and response to therapies used.

Therefore, the loss of coherence between micro and macro hemodynamic parameters is one of the reasons that suggest a compelling need for microvascular monitoring at bedside in ICU patients $[59,60]$. 
The other argument that may support the push toward a need for microvascular assessment in ICU COVID-19 patients may be considered the lack or, at least, the poor knowledge that the medical community still has about COVID-19.

The COVID-19 has caused a tremendous earthquake in our ordinary lives but it has also hit, in particular our national health systems. In all countries the ICUs have been stressfully overwhelmed by the continuous request of beds availability.

This pneumonia that causes ARDS with urgent needs of assisted pulmonary ventilation has surprised us and it was a completely new illness.

In the first weeks from the COVID-19 outbreak, patients with general acute hypoxia and systemic acidosis have been treated with mechanical respiratory assistance and with all the possible treatments disposable. A mainstay has been the comprehension that CS was the key factor to fight with the opening to the cytokine's actions treatments with rapid successful outcomes in many cases. The following step was the treatment of hypercoagulation with heparin with the evident reduction of mortality associated with pulmonary embolism, myocardial infarction, or intravascular disseminated coagulation.

If we could have had soon the possibility to monitor the patient microcirculatory function at the bedside, perhaps much many lives could have been saved.

But of course, these are hypotheses and we need pieces of evidence in medicine.

Maybe the COVID-19 emergency has spotlighted again the role of bedside microvascular assessment in the scenario of ICU patients.

The microcirculatory diagnostic has already proved to have a good prognostic value in clinical practice in not ICU patients. The nailfold capillaroscopy or transcutaneous oxygen pressure measurement (TcpO2) are routinely used, the first in the diagnostic pathway of the Raynaud's phenomenon, the latter in the selecting critical limb ischemia and predicting healing of skin lesions [61, 62].

Therefore, the bedside evaluation of microcirculation could be also useful in the diagnostic and therapeutic pathways of ICU patients.

Many colleagues have struggled with a substantially unknown disease such as COVID-19 [63].

During these times, frequently they required advice to angiologists or vascular medicine specialists about the sign and symptoms to monitor patients' microcirculatory functional status.

The D-dimer, the neutrophil to lymphocyte ratio, as well as thrombocytopenia, lymphopenia, or IL-6. Levels and ratio have been defined as predictive values of mortality in the COVID-19 [7].

These alterations if associated with direct functional morphological evaluation such as HVM might increase the predictivity of the values reported.

Finally, it is likely that also the assessment of microcirculation for the monitoring of treatment could be of help. The effects of mechanical ventilatory assistance and the effects of drug inhibition on CS such as tocilizumab inhibitor of the IL- 6 could be implemented by the bedside microcirculation investigation [64].

In conclusion all the above-reported considerations support the compelling necessity of microvascular assessment in ICU patients. This old but recurrent problem is recently exploded with the COVID-19 outbreak because of the absence of specific knowledge and treatments of the disease.

The need to go beyond the current monitoring modalities sounds like "Plus Ultra" in reply to "Hic Sunt Leones" of the current status of this new disease.

This review, despite its limits, aimed to diffuse some elements to increase investigation on microcirculation at the bedside in ICU patients with the hope to be of such help.

\section{References}

[1] Zhou P, Yang XL, Wang XG, Hu B, Zhang L, Zhang W, et al. A pneumonia outbreak associated with a new coronavirus of probable bat origin. Nature. 2020;579:270-273. 
[2] Guan WJ, Ni ZY, Hu Y, Liang WH, Ouk CQ, He JX et al. Clinical characteristics of coronavirus disease 2019 in China. N Engl J Med. 2020; DOI:10.1056/NEJMoa2002032

[3] World Health Organization. Director-General's remarks at the media briefing on 2019-nCoV on 11 February 2020. https://www.who.int/dg/speeches/detail/who-director-general-s-remarks-at-the-media-briefing-on-2019-ncov-on-11february-2020

[4] Ministero della Salute (2020). http://www.salute.gov.it/portale/nuovocoronavirus

[5] Li L, Huang T, Wang Y, Wang P, Liang Y, et al. COVID-19 patients' clinical characteristics, discharge rate, and fatality rate of Meta-Analysis. Med Virol. 2020 Mar 12. doi:10.1002/jmv.25757

[6] Remuzzi A, Remuzzi G. COVID-19 and Italy: What Next? Lancet 2020. doi: 10.1016/S0140-6736(20)30627-9

[7] China National Health Commission. Diagnosis and treatment of novel coronavirus pneumonia in China (trial version 7). https://www.who.int/docs/default-source/wpro—documents/countries/china/covid-19-briefing-nhc/1clinical-protocols-for-thediagnosis-and-treatment-of-covid-19-7.pdf?sfvrsn=c6cbfba4_2

[8] Bikdeli B, Madhavan MV, Jimenez D. COVID-19 and Thrombotic or Thromboembolic Disease: Implications for Prevention, Antithrombotic Therapy, and Follow-up. J Am Coll Cardiol. 2020; Apr 15:S0735-1097(20)35008-7. doi: 10.1016/j.jacc.2020.04.031

[9] Panigada M, Bottino N, Tagliabue P, Grasselli G, Novembrino C, Chantarangkul V, et al. Hypercoagulability of COVID19 patients in Intensive Care Unit. A Report of Thromboelastography Findings and other Parameters of Hemostasis. J Thromb Haemost. 2020; doi: 10.1111/jth.14850

[10] Ye Q, Wang B, Mao J The Pathogenesis and Treatment of the 'Cytokine Storm' in COVID-19. J Infect. 2020;S01634453(20)30165-1. doi: 10.1016/j.jinf.2020.03.037

[11] Hawiger J, Veach RA, Zienkiewicz J. New paradigms in sepsis: from prevention to protection of failing microcirculation. J Thromb Haemost 2015;13:1743-56.

[12] Jung EM, Stroszczinski C, Jung F. Contrast enhanced ultrasonography (CEUS) to detect abdominal microcirculatory disorders in severe cases of COVID-19 infection: First experience. Hemorheology and Microcirculation 2020. DOI:10.3233/CH-209003

[13] Scavone C, Brusco S, Bertini M, Sportiello L, Rafaniello C, Zoccoli A. Current pharmacological treatments for COVID19: what's next? Br J Pharmacol. 2020; doi: 10.1111/bph.15072

[14] Salvi R, Patankar P. Emerging pharmacotherapies for COVID-19. Biomed Pharmacother. 2020. doi: 0.1016/j.biopha.2020110267

[15] Guven G, Hilty MP, Ince C. Microcirculation: Physiology, Pathophysiology, and Clinical Application. Blood Purif 2020;49:143-150.

[16] Miranda M, Balarini M, Caixeta D, Bouskela E. Microcirculatory dysfunction in sepsis: pathophysiology, clinical monitoring, and potential therapies Am J Physiol Heart Circ Physiol. 2016;311:H24-H35.

[17] Pranskunas A, Koopmans M, Koetsier PM, Pilvinis V, Boerma EC. Microcirculatory blood flow as a tool to select ICU patients eligible for fluid therapy. Intensive Care Med. 2013;39:612-9. 50

[18] Bouattour K, Teboul JL, Varin L, Vicaut E, Duranteau J. Preload dependence is associated with reduced sublingual microcirculation during major abdominal surgery. Anesthesiology. 2019;130(4):541-9.

[19] Huang C, Wang Y, Li X, Ren L, Zhao J, Hu Y, et al. Clinical features of patients infected with 2019 novel coronavirus in Wuhan, China. Lancet 2020;395:497-506.

[20] Shaw AC, Goldstein DR, Montgomery RR. Age-dependent dysregulation of innate immunity. Nature reviews Immunology. 2013;13,12:875-87.

[21] Law HKW, Cheung CY, Ng HY, Sia SF, Chan YO, Luk W, et al. Chemokine up-regulation in SARS-coronavirus-infected, monocyte-derived human dendritic cells. Blood. 2005;106,7:2366-74.

[22] Cheung CY, Poon LLM, Ng IHY, Luk W, Sia SF, Wu MHS, et al. Cytokine responses in severe acute respiratory syndrome coronavirus-infected macrophages in vitro: possible relevance to pathogenesis. Journal of virology. 2005;79:7819-26.

[23] Lau SKP, Lau CCY, Chan KH, Li CPY, Chen H, Jin DY, et al. Delayed induction of proinflammatory cytokines and suppression of innate antiviral response by the novel Middle East respiratory syndrome coronavirus: implications for pathogenesis and treatment. The Journal of general virology. 2013;94(12):2679-90.

[24] Channappanavar R, PerlmanS. Pathogenic human coronavirus infections: causes and consequences of cytokine storm and immunopathology. Semin Immunopathol 2017;39:529-539.

[25] Conti P, Ronconi, G, Caraffa A, Gallenga CE, Ross R, Frydas I, et al. Induction of pro-inflammatory cytokines (IL-1 and IL-6) and lung inflammation by Coronavirus -19 (COVI-19 or SARS-CoV-2): anti-inflammatory strategies, J Biol Regul Homeost Agents. 2020,34. DOI: 10.23812

[26] Chousterman BG, Swirski FK, Weber GF. Cytokine storm and sepsis disease pathogenesis. Seminars in Immunopathology. 2017;39(5):517-28. 
[27] Zhang DX, Gutterman DD Mitochondrial reactive oxygen species-mediated signaling in endothelial cells. Am J Physiol Heart Circ Physiol. 2007;292:H2023-2031.

[28] Goldenberg NM, Steinberg BE, Slutsky AS, Lee WL. Broken barriers: a new take on sepsis pathogenesis. Sci Transl Med. 2011;3(88):88ps25.

[29] Hernandez G, Bruhn A, Ince C. Microcirculation in sepsis: new perspectives. Curr Vasc Pharmacol. 2013;11:161-169.

[30] Bateman RM, Jagger JE, Sharpe MD, Ellsworth ML, Mehta S, Ellis CG. Erythrocyte deformability is a nitric oxidemediated factor in decreased capillary density during sepsis. Am J Physiol Heart Circ Physiol. 2001;280:H2848-H2856.

[31] Hanley B, Lucas SB, Youd E, Swift B, Osborn M. Autopsy in suspected COVID-19 cases J Clin Pathol 2020;73:239-242.

[32] Krüger-Genge A, Blocki A, Franke RP, Jung F. Vascular Endothelial Cell Biology: An Update. Int J Mol Sci. 2019;20(18). doi: 10.3390/ijms20184411

[33] Kremer A, Wußmann M, Herrmann M, Raghunath M, Walles H. Ciclopiroxolamine promotes the angiogenic response of endothelial cells and mesenchymal stem cells. Clin Hemorheol Microcirc 2019;73(2):317-328. doi: 10.3233/CH-190559

[34] Pieles GE, Alkon J, Manlhiot C, Fan CS, Kinnear C, Benson LN. Association between genetic variants in the HIF1AVEGF pathway and left ventricular regional myocardial deformation in patients with hypertrophic cardiomyopathy. Pediatr Res. 2020. doi: 10.1038/s41390-020-0929

[35] Lapi D, Vagnani S, Sapio D, Mastantuono T, Sabatino L, Paterni M, et al. Long-term remodelling of rat pial microcirculation after transient middle cerebral artery occlusion and reperfusion. J Vasc Res. 2013;50(4):332-45.

[36] Sun H, Ringdahl U, Homeister JW, Fay WP, Engleberg NC, Yang AY, et al. Plasminogen is a critical host pathogenicity factor for group A streptococcal infection. Science 2004;305:1283-6.

[37] Borges AH, O'Connor JL, Phillips AN, Baker JV, Vjecha MJ, et al. Factors associated with D-dimer levels in HIVinfected individuals. PLoS One. 2014;9(3):e90978. doi: 10.1371

[38] Ramacciotti E, Agati LB, Aguiar VCR, Wolosker N, Guerra JC, de Almeida RP. et al. Zika and Chikungunya Virus and Risk for Venous Thromboembolism. Clin Appl Thromb Hemost. 2019; 25:1076029618821184. doi: $10.1177 / 1076029618821184$

[39] Mehta P, McAuley DF, Brown M, Sanchez E, Tattersall RS, Manson JJ, et al. COVID-19: consider cytokine storm syndromes and immunosuppression. Lancet. 202028;395(10229):1033-1034. doi: 10.1016/S0140-6736(20)30628-0

[40] Esmon CT, Esmon NL. The link between vascular features and thrombosis. Annu Rev Physiol 2011;73:503-14.

[41] Levi M, ten Cate H, Bauer KA, van der Poll T, Edgington TS, Büller HR, et al. Inhibition of endotoxin-induced activation of coagulation and fibrinolysis by pentoxifylline or by a monoclonal anti-tissue factor antibody in chimpanzees. J Clin Invest. 1991;93:114-120.

[42] Vincent JL, Rello J, Marshall J, Silva E, Anzueto A, Martin CD, et al. International study of the prevalence and outcomes of infection in intensive care units. JAMA. 2009;302:2323-2329.

[43] Ferrara G, Edul VS, Canales HS, Martins E, Canullán C, Murias G, et al. Systemic and microcirculatory effects of blood transfusion in experimental hemorrhagic shock. Intensive Care Med Exp. 2017;5(1):24.

[44] Verdant CL, De Backer D, Bruhn A, Clausi CM, Su F, Wang Z, et al. Evaluation of sublingual and gut mucosal microcirculation in sepsis: a quantitative analysis. Crit Care Med. 2009;37(11):2875-81.

[45] Lima A, van Rooij T, Ergin B, Sorelli M, Ince Y, Specht PA, et al. Dynamic Contrast-Enhanced Ultrasound Identifies Microcirculatory Alterations in Sepsis-Induced Acute Kidney Injury. Crit Care Med. 2018;46(8):1284-92. 23-25

[46] Top AP, Ince C, van Dijk M, Tibboel D. Changes in buccal microcirculation following extracorporeal membrane oxygenation in neonates with severe respiratory failure. Crit Care Med. 2009;37(3):1121-4.

[47] Edul VS, Enrico C, Laviolle B, Vazquez AR, Ince C, Dubin A. Quantitative assessment of the microcirculation in healthy volunteers and in patients with septic shock. Crit Care Med. 2012;40(5):1443-8. 18.

[48] Massey MJ, Hou PC, Filbin M, Wang H, Ngo L, Huang DT, et al. ProCESS investigators. Microcirculatory perfusion disturbances in septic shock: results from the ProCESS trial. Crit Care. 2018;22(1):308.

[49] De Backer D, Creteur J, Preiser JC, Dubois MJ, Vincent JL. Microvascular blood flow is altered in patients with sepsis. Am J Respir Crit Care Med. 2002;166(1):98-104.

[50] Tachon G, Harrois A, Tanaka S, Kato H, Huet O, Pottecher J, et al. Microcirculatory alterations in traumatic hemorrhagic shock. Crit Care Med. 2014;42(6):1433-41.

[51] Kara A, Akin S, Dos Reis Miranda D, Struijs A, Caliskan K, van Thiel RJ, et al. Microcirculatory assessment of patients under VA-ECMO. Crit Care. 2016;20(1):344.

[52] Scorcella C, Damiani E, Domizi R, Pierantozzi S, Tondi S, Carsetti A, et al. Micro- DAIMON study: Microcirculatory DAIly MONitoring in critically ill patients: a prospective observational study. Ann Intensive Care. 2018;8(1):6-22.

[53] Ince C, Boerma EC, Cecconi M, De Backer D, Shapiro NI, Duranteau J, et al. Cardiovascular Dynamics Section of the ESICM. Second consensus on the assessment of sublingual microcirculation in critically ill patients: results from a task force of the European Society of Intensive Care Medicine. Intensive Care Med. 2018;44(3):281-99. 
[54] De Backer D, Ospina-Tascon G, Salgado D, Favory R, Creteur J, Vincent JL. Monitoring the microcirculation in the critically ill patient: current methods and future approaches. Intensive Care Med. 2010;36:1813-1825.

[55] Jones AE, Shapiro NI, Trzeciak S, Arnold RC, Claremont HA, Kline. Lactate clearance vs. central venous oxygen saturation as goals of early sepsis therapy: a randomized clinical trial. JAMA 201;303:739-746.

[56] Iba T, Okamoto K, Ohike T, Tajirika T, Aihara K, Watanabe S, Kayhanian H. Enoxaparin and fondaparinux attenuates endothelial damage in endotoxemic rats. J Trauma Acute Care Surg. 2012;72:177-182

[57] Hoffmann JN, Vollmar B, Römisch J, Inthorn D, Schildberg FW, Menger MD. Antithrombin effects on endotoxininduced microcirculatory disorders are mediated mainly by its interaction with microvascular endothelium. Crit Care Med. 2002;30:218-225.

[58] Paize F, Sarginson R, Makwana N, Baines PB, Thomson AP, Sinha I, et al. Changes in the sublingual microcirculation and endothelial adhesion molecules during the course of severe meningococcal disease treated in the paediatric intensive care unit. Intensive Care Med. 2012;38:863-871.

[59] Ince C, Sinaasappel M. Microcirculatory oxygenation and shunting in sepsis and shock. Crit Care Med. 1999;27:13691377.

[60] Trzeciak S, Cinel I, Phillip Dellinger R, Shapiro NI, Arnold RC, Parrillo JE, Hollenberg SM. Resuscitating the microcirculation in sepsis: the central role of nitric oxide, emerging concepts for novel therapies, and challenges for clinical trials. Acad Emerg Med. 2008;15:399-413.

[61] Smith V, Herrick AL, Ingegnoli F, Damjanov N, De Angelis R, Denton CP et al. EULAR Study Group on Microcirculation in Rheumatic Diseases and the Scleroderma Clinical Trials Consortium Group on Capillaroscopy Standardisation of nailfold capillaroscopy for the assessment of patients with Raynaud's phenomenon and systemic sclerosis. Autoimmun Rev. 2020;19(3):102458. doi: 10.1016/j.autrev.2020.102458

[62] Frank U, Nikol S, Belch J, Boc V, Brodmann M, Carpentier PH, et al. ESVM Guideline on peripheral arterial disease. Vasa. 2019;48(Suppl 102):1-79. doi: 10.1024/0301-1526/a000834

[63] Jung F, Krieger V, Hufert FT, Küpper J-H. How we should respond to the CoronavirusSARS-CoV-2 outbreak: A German perspective. Clin Hemorheol Microcirc. 2020. DOI: 10.3233/CH-170277

[64] Allam SR, Dao A, Madhrira MM, Antiporta PB, Nair RR, Guiteau JJ, Reyad AI. Interleukin-6 Receptor Antagonist Therapy to Treat SARS-CoV-2 Driven Inflammatory Syndrome in a Renal Transplant Recipient. Transpl Infect Dis.2020 May 14:e13326. doi: 10.1111/tid.13326 